\title{
Evaluasi Layanan Sistem Informasi Akademik Berbasis Cobit 4.1 Pada Universitas Semarang
}

\author{
Prind Triajeng Pungkasanti ${ }^{1}$, Didin Herlinudinkhaji ${ }^{2}$ \\ ${ }^{1}$ Fakultas Teknologi Informasi dan Komunikasi Universitas Semarang \\ Jl. Soekarno Hatta Semarang, telp/fax (024) 6702757/ (024) 6702272, e-mail: prind@usm.ac.id \\ ${ }^{2}$ Fakultas IImu Komputer Universitas Selamat Sri \\ Jl. Soekarno Hatta Km. 3 Kendal, telp/fax, e-mail: didnt.aji@gmail.com
}

ARTICLE INFO

\section{Article history:}

Received 8 Agustus 2018

Received in revised form 10 Agustus

2018

Accepted 14 September 2018

Available online 17 Agustus 2018

\begin{abstract}
Pemanfaatan Sistem Informasi Akademik (SIA) untuk mahasiswa sangat diperlukan, begitu juga pada SIA Universitas Semarang (USM). SIA dibangun untuk memudahkanahasiswa dapat mengetahui informasi berkaitan dengan akademik dapat mengakses pada alamat http://sia.usm.ac.id/. Informasi yang disampaikan SIA diantaranya informasi jadwal pengisian KRS, jadwal kuliah, dan kalender akademik. Dengan SIA mahasiswa dapat mengetahui informasi yang berkaitan dengan perkuliahan tanpa harus datang ke kampus. Namun evaluasi untuk SIA diperlukan sebagai peningkatan layanan, keamanan, kenyamanan, dan kecepatan yang dapat diperoleh dari layanan SIA. Evaluasi terhadap layanan SIA berbasis COBIT pada USM ini dikerjakan dengan menyebarkan kuesioner kepada mahasiswa sebagai pengguna SIA. Hasil kuesioner ini diolah dengan menggunakan SPSS dan dianalisa dengan menggunakan parameter COBIT.
\end{abstract}

Keywords: evalusi layanan SIA; evaluasi layanan COBIT 4.1; evaluasi; layanan pelanggan sistem

\section{Pendahuluan}

Informasi merupakan kebutuhan paling utama dalam proses manajemen sehingga era sekarang merupakan zaman informasi atau dikenal dengan information based society (Sarno dan Iffano, 2009) [1]. Sehingga informasi harus dijaga dari kejahatan-kejahatan informasi dan kejahatan cybercrime atau dikenal dengan sebutan kejahatan dunia maya.

Sistem informasi menjadi senjata utama organisasi untuk mencapai tujuan organisasi. Oleh karena itu pembangunan tata kelola teknologi informasi akan menghasilkan sistem informasi yang handal. Untuk membuat sistem informasi yang handal organisasi perlu membuat strategi, metode, dan evaluasi terhadap layanan sistem informasi yang menjadi kebutuhan bagi organisasi (Iden dan Eikebrokk, 2012) [2]. Dengan melakukan tata kelola sistem informasi, organisasi dapat meningkatkan kualitas layanan sistem informasi, mengurangi resiko, meningkatkan kinerja dan mengurangi biaya layanan sistem informasi (Jogiyanto dan Abdillah, 2011) [3].

Universitas Semarang merupakan salah satu universitas di Semarang dengan jumlah mahasiswa yang sangat besar. Hal ini yang kemudian menjadikan alasan pemanfaatan Sistem Informasi Akademik (SIA) untuk mahasiswa sangat diperlukan. Aplikasi Sistem Informasi Akademik ini dibangun untuk membantu proses belajar dan mengajar dalam akademik ataupun aplikasi lain yang terkait dan untuk memudahkan Universitas Semarang dalam mengolah datadatanya. Aplikasi ini telah melalui 4 versi, yakni versi Alpha,Versi Beta, Versi Stabil 1.0 dan Versi Stabil 1.1. Sistem yang di pakai sekarang adalah versi Stabil 1.1, karena telah melalui proses evaluasi dari beberapa sistem. Mahasiswa dapat mengetahui informasi berkaitan dengan akademik 
dapat mengakses pada alamat http://sia.usm.ac.id/. Informasi yang disampaikan SIA diantaranya informasi jadwal pengisian KRS, jadwal kuliah, dan kalender akademik. Dengan SIA mahasiswa dapat mengetahui informasi yang berkaitan dengan perkuliahan tanpa harus datang ke kampus.

Supaya organisasi dalam mengelola sistem informasi menjadi lebih terarah maka harus terdapat evaluasi terhadap sistem tersebut sehingga sistem informasi menjadi terarah sesuai dengan tujuan organisasi. Evaluasi sistem informasi dilakukan untuk dapat menilai apakah sistem informasi yang digunakan telah dapat menjaga integritas data, dapat membantu pencapaian tujuan organisasi secara efektif, serta menggunakan sumber daya yang dimiliki secara efisien (Weber, 2000) [4]. Salah satu cara untuk mengevaluasi terhadap sistem informasi adalah dengan menguji keamanan entitas informasi, entitas informasi itu terdiri dari manusia, perangkat lunak, perangkat keras, multimedia, dan jaringan (Singleton, 2012) [5].

\section{Metode Penelitian}

\subsection{Control Objective for Information and Related Technology (COBIT)}

COBIT adalah Control Objectives for Information and Related Technology yang merupakan audit sistem informasi dan dasar pengendalian yang dibuat oleh Information Systems Audit and Control Association (ISACA), dan IT Governance Institute (ITGI) pada tahun 1992. COBIT merupakan sekumpulan dokumentasi best practice untuk tata kelola TI yang dapat membantu auditor, pengguna sistem, dan manajemen dalam menjembatani risiko organisasi, kebutuhan pengendalian, dan masalah - masalah teknis TI.. Kepercayaan pelanggan meningkat setelah internet banking menggunakan tata kelola TI berdasarkan kerangka kerja COBIT (Huang, 2011) [6]. COBIT selain sebagai sistem penjamin keamanan informasi juga sebagai rerangka sistem tata kelola teknologi informasi yang terintegrasi dengan sistem organisasi lain melalui serangkaian 34 proses (Jogiyanto dan Abdillah, 2011) [3].

Karakteristik utama kerangka kerja COBIT adalah fokus pada bisnis, orientasi pada proses, berbasis kontrol, dan dikendalikan oleh pengukuran, sedangkan prinsip yang mendasarinya adalah untuk menyediakan informasi yang diperlukan organisasi dalam mewujudkan tujuannya, organisasi perlu mengelola dan mengendalikan sumber daya teknologi informasi dengan menggunakan sekumpulan proses-proses yang terstruktur untuk memberikan layanan informasi yang diperlukan.

Aktivitas teknologi informasi dalam COBIT didefiniskan ke dalam model proses yang umum dan dikelompokkan dalam 4 (empat) domain yang ditunjukkan oleh Gambar 1, antara lain:

1. Perencanaan dan Pengorganisasian (Plan and Organise)

2. Pengadaan dan Implementasi (Acquisition and Implementation)

3. Penyampaian Layanan dan Dukungan (Delivery and Support)

4. Monitor dan Evaluasi (Monitoring and Evaluation)

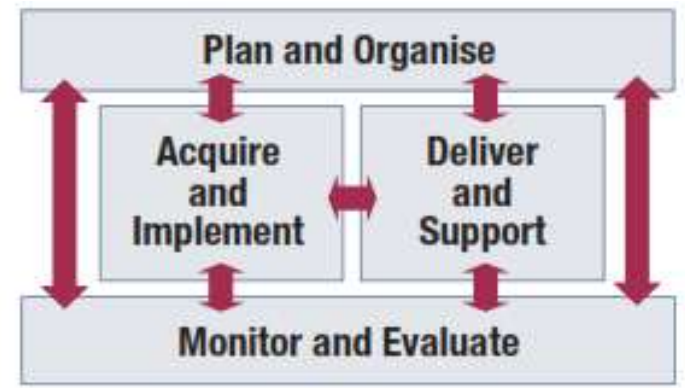

Gambar 1 Domain COBIT

Perencanaan IT didalam bisnis tidak lepas dari Business Goals dan IT Goals. Perencanaan strategis yang didukung dengan keseimbangan TI Goals dengan Business Goals merupakan komponn utama dalam bisnis / IT (IT Governance Institute, 2008). Keterhubungan Business Goals dengan IT Goals terjadi dimana Business Goals menjadi dasar tujuan pengembangan IT dan untuk mengaplikasikannya ditentukan IT Goals dalam merealisasikan tujuan tersebut seperti yang digambarkan dalam Gambar 2. 


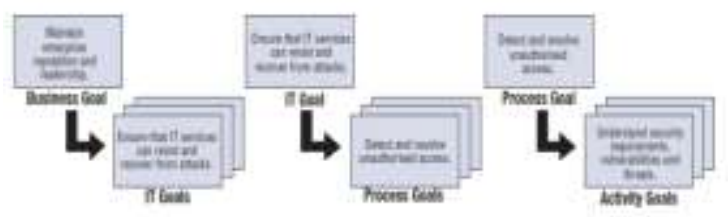

Gambar 2. Goal Relationship

Dalam melakukan evaluasi terhadap sistem diperlukan pedoman kerja yang digunakan melakukan evaluasi terhadap sistem agar sejalan dengan tujuan organisasi. COBIT menyediakan framework yang digunakan sebagai pedoman tersebut. Adapun framework COBIT digambarkan dalam Gambar 3.

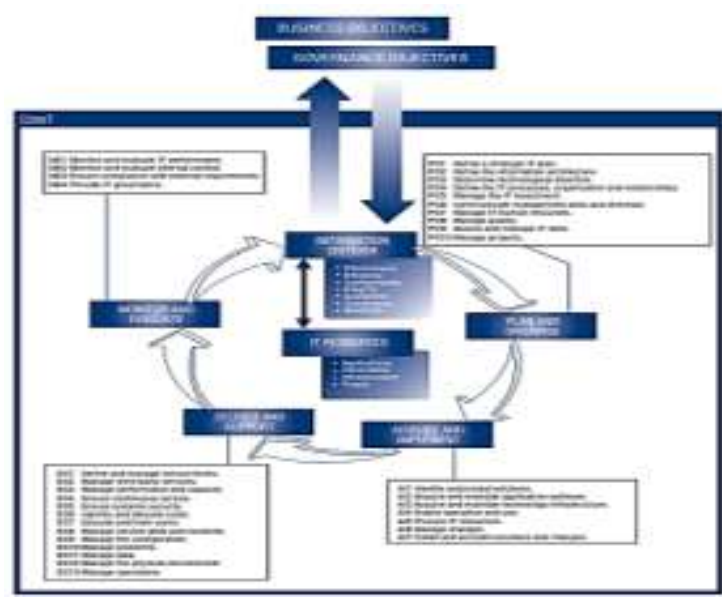

Gambar 3. Framework COBIT

\subsection{Uji Validitas dan Realibilitas}

Uji validitas erat kaitannya dengan keaktualan data dikatakan valid ataukah tidak. Pengukuran dikatakan valid jika mengukur tujuannya dengan nyata atau benar dan pengukuran dikatakan tidak valid jika pengukurannya menyimpang dari tujuannya (Jogiyanto, 2011) [7].

$$
r=\frac{t}{\sqrt{d f+t^{2}}}
$$

dimana :

$\mathrm{r}=\mathrm{r}$ tabel

$\mathrm{t}=\mathrm{t}$ tabel

$\mathrm{df}=$ derajat bebas

Uji reliabilitas erat kaitannya dengan seberapa akurat dapat diandalkan. Pengukuran yang reliabel (dapat diandalkan) adalah pengukuran yang dapat dipercaya. Pengukuran yang dapat dipercaya adalah pengukuran yang akurat dan konsisten (jogiyanto, 2011) [7] terhadap beberapa subjek yang sama dan diperoleh hasil yang tidak berbeda. Reliabilitas yang digunakan dengan menghitung korelasi total antaritem (jogiyanto, 2011) [7] dan cronbach's alpha. Perhitungan reliabilitas korelasi total antaritem terlebih dahulu mencari korelasi antaritem kemudian menjumlahkan total korelasi semua item yang diuji dibagi jumlah item.

$$
\alpha=\frac{k}{k-1}\left(\frac{\sum \sigma_{x i}^{2}}{\sigma_{x}^{2}}\right)
$$


Keterangannya adalah sebagai berikut :

$\alpha=$ Cronbach's Coefficient Alpha

$\mathrm{k}=$ jumlah pecahan

$\sum \sigma_{x i}^{2}=$ total dari varian masing-masing pecahan

$\sigma_{x i}^{2}=$ varian dari total skor

Tabel 1. Batasan Skor Reliabilitas Cronbach's Alpha

\begin{tabular}{|l|l|}
\hline Skor & Reliabilitas \\
\hline$<0,50$ & Rendah \\
\hline $0,50-0,59$ & Cukup \\
\hline $0,60-0,79$ & Tinggi \\
\hline $0,80-1,00$ & Sangat Tinggi \\
\hline
\end{tabular}

\section{Analisa dan Pembahasan}

\subsection{Uji Validitas}

Dari hasil pengukuran validitas dapat dikatakan bahwa item yang digunakan valid atau tidak. Tabel 2 menunjukkan hasil dari pengukuran validitas untuk kuesioner pengguna dengan jumlah responden sebanyak 206 dan taraf signifikansi 5\%.

Tabel 2. Validitas Kuesioner Mahasiswa

\begin{tabular}{|c|c|c|c|c|}
\hline Variabel & Item & r hitung & $r$ tabel & Keterangan \\
\hline Layanan & SIA1 & 0,7 & 0,136 & Valid \\
\hline \multirow{5}{*}{ SIA USM } & SIA2 & 0,6 & 0,136 & Valid \\
\hline & SIA3 & 0,6 & 0,136 & Valid \\
\hline & SIA4 & 0,6 & 0,136 & Valid \\
\hline & SIA5 & 0,6 & 0,136 & Valid \\
\hline & SIA6 & 0,6 & 0,136 & Valid \\
\hline \multirow{11}{*}{$\begin{array}{l}\text { Layanan Kartu } \\
\text { Rencana Studi } \\
\text { (KRS) }\end{array}$} & KRS1 & 0,7 & 0,136 & Valid \\
\hline & KRS2 & 0,6 & 0,136 & Valid \\
\hline & KRS3 & 0,7 & 0,136 & Valid \\
\hline & KRS4 & 0,7 & 0,136 & Valid \\
\hline & KRS5 & 0,7 & 0,136 & Valid \\
\hline & KRS6 & 0,6 & 0,136 & Valid \\
\hline & KRS7 & 0,6 & 0,136 & Valid \\
\hline & KRS8 & 0,6 & 0,136 & Valid \\
\hline & KRS9 & 0,5 & 0,136 & Valid \\
\hline & KRS10 & 0,6 & 0,136 & Valid \\
\hline & KRS11 & 0,5 & 0,136 & Valid \\
\hline \multirow{3}{*}{$\begin{array}{c}\text { Layanan Jadwal } \\
\text { Kuliah }\end{array}$} & JDWL1 & 0,5 & 0,136 & Valid \\
\hline & JDWL 2 & 0,7 & 0,136 & Valid \\
\hline & JDWL 3 & 0,7 & 0,136 & Valid \\
\hline \multirow{3}{*}{$\begin{array}{c}\text { Layanan Materi } \\
\text { Kuliah }\end{array}$} & MAT1 & 0,7 & 0,136 & Valid \\
\hline & MAT2 & 0,7 & 0,136 & Valid \\
\hline & MAT3 & 0,7 & 0,136 & Valid \\
\hline \multirow{4}{*}{ Sistem Informasi } & SI1 & 0,7 & 0,136 & Valid \\
\hline & SI2 & 0,7 & 0,136 & Valid \\
\hline & SI3 & 0,6 & 0,136 & Valid \\
\hline & SI4 & 0,7 & 0,136 & Valid \\
\hline
\end{tabular}




\subsection{Uji Reliabilitas}

Pengujian reliabilitas diperlukan untuk mengetahui reliabilitas masing-masing variabel. Tabel 3 manunjukkan hasil pengujian reliabilitas.

Tabel 3. Hasil Pengujian Reliabilitas

\begin{tabular}{|c|c|c|c|}
\hline Variabel & $\begin{array}{c}\text { Cronbach's } \\
\text { Alpha }\end{array}$ & $\mathbf{r}$ tabel & Keterangan \\
\hline Layanan SIA USM & 0,815 & 0,136 & Reliabel \\
\hline Layanan KRS & 0,880 & 0,136 & Reliabel \\
\hline Layanan Jadwal Kuliah & 0,778 & 0,136 & Reliabel \\
\hline Layanan Materi Kuliah & 0,847 & 0,136 & Reliabel \\
\hline Sistem Informasi & 0,798 & 0,136 & Reliabel \\
\hline
\end{tabular}

\subsection{Uji Korelasi}

Uji korelasi digunakan untuk mengetahui hubungan antar variabel. Gambar 4.1 menunjukkan hubungan antar variabel.

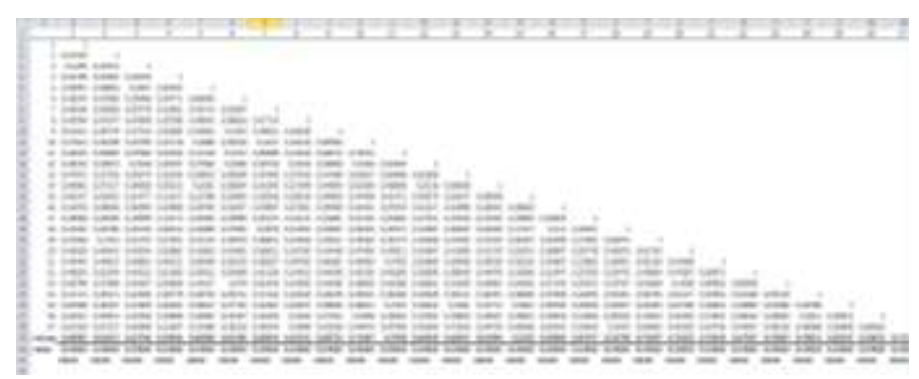

Gambar Error! No text of specified style in document.. Korelasi Antar Item

\subsection{Hasil Tanggapan Responden}

Hasil responden berdasarkan kelompok layanan ditunjukkan oleh Tabel 4.

Tabel 4. Hasil tanggapan responden masing-masing item

\begin{tabular}{|l|l|l|c|}
\hline Variabel & Item & Nilai & Rerata \\
\hline Layanan & SIA1 & 732 & \\
SIA & SIA2 & 757 & \\
USM & SIA3 & 707 & さ \\
& SIA4 & 694 & \\
& SIA5 & 750 & \\
& SIA6 & 701 & \\
\hline & KRS1 & 697 & \\
Layanan & KRS2 & 740 & \\
Kartu & KRS3 & 732 & \\
Rencana & KRS4 & 715 & $\stackrel{8}{\text { Studi }}$ \\
KRS5 & 728 & \\
(KRS) & KRS6 & 738 & \\
& KRS7 & 746 & \\
\hline
\end{tabular}




\begin{tabular}{|c|c|c|c|}
\hline Variabel & Item & Nilai & Rerata \\
\hline & $\begin{array}{l}\text { KRS8 } \\
\text { KRS9 } \\
\text { KRS10 } \\
\text { KRS11 }\end{array}$ & $\begin{array}{l}730 \\
710 \\
670 \\
577\end{array}$ & \\
\hline $\begin{array}{l}\text { Layanan } \\
\text { Jadwal } \\
\text { Kuliah }\end{array}$ & $\begin{array}{l}\text { JDWL1 } \\
\text { JDWL } 2 \\
\text { JDWL } 3\end{array}$ & $\begin{array}{l}774 \\
747 \\
730\end{array}$ & ำ \\
\hline $\begin{array}{l}\text { Layanan } \\
\text { Materi } \\
\text { Kuliah }\end{array}$ & $\begin{array}{l}\text { MAT1 } \\
\text { MAT2 } \\
\text { MAT3 }\end{array}$ & $\begin{array}{l}724 \\
657 \\
723\end{array}$ & \\
\hline $\begin{array}{l}\text { Sistem } \\
\text { Informasi }\end{array}$ & $\begin{array}{l}\text { SI1 } \\
\text { SI2 } \\
\text { SI3 } \\
\text { SI4 }\end{array}$ & $\begin{array}{l}726 \\
707 \\
647 \\
697\end{array}$ & 8) \\
\hline
\end{tabular}

Dari hasil tanggapan responden maka dapat disimpulkan bahwa rata-rata score yang diperoleh diangka 600 sampai 700. Score tersebut masih dalam kategori baik berdasarkan tabel score pada gambar 5 .

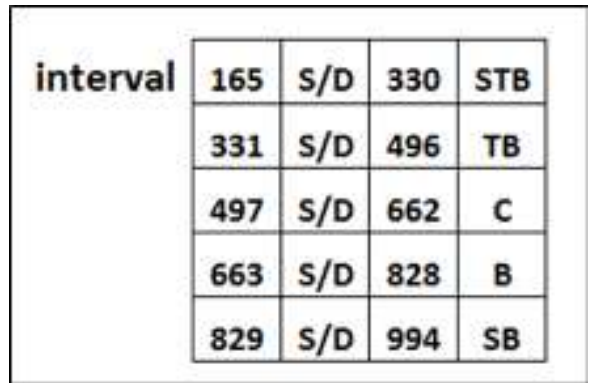

Gambar 5. Interval Score

\section{Kesimpulan}

Kesimpulan yang dapat penulis sajikan dalan penelitian ini adalah: Berdasarkan hasil dari evaluasi SIA dengan menggunakan COBIT sebagian besar layanan SIA USM sudah baik dengan score 715 dan Layanan pengisian KRS yang ada pada SIA USM berada dalam kategori cukup karena berdasarkan dari hasil kuesioner yang disebarkan kepada mahasiswa, layanan pengisian KRS USM masih sering mengalami error.

Agar sistem informasi ini dapat berjalan secara maksimal, ada beberapa hal yang penulis sarankan: Layanan SIA baik untuk dari KRS, KHS dan lainnya perlu ditingkatkan dan Kapasitas bandwidth perlu dikaji ulang agar layanan menjadi lebih baik. 


\section{Daftar Pustaka}

[1] Sarno, Riyanarto dan Tiffano, Irsyat, Sistem Manajemen Keamanan Informasi berbasis ISO 27001, Surabaya: ITS Press. 2009.

[2] Iden, J, dan Eikebrokk, T.T., Implementing IT Service Management: A systematic literature review, International Journal of Information Management 33, 2013: 512- 523.

[3] Jogiyanto dan Abdillah, Willy, Sistem Tata Kelola Teknologi Informasi, Yogyakarta : ANDI Offset. 2011.

[4] Weber, Ron, Informatioin System Control and Audit, The University of Queensland, Prentice Hall Inc. 2000.

[5] Singleton, Tommie dan Hall, James, Audit Teknologi Informasi dan Assurance, Jakarta: Salemba Empat. 2009.

[6] Huang, Shi-Ming, Shen, Wei-Cheng, Yen, David, C., Chou, Ling-Yi, 2011, IT Governance : Objectives and assurances in internet banking, Journal Advance in International Acounting 27, 406-414.

[7] Jogiyanto, Pedoman Survey Kuesioner, Yogyakarta: BPFE. 2011. 